\title{
Water turnover rates of a wheelchair rugby squad during an international tournament
}

\author{
Katherine Black, Ronald Maughan and Susan Shirreffs \\ Loughborough University, Loughborough, UK
}

Individuals with a spinal cord injury (SCI) suffer a greater number of urinary tract infections and hyponatraemia; the prevalence rate for hyponatraemia is approximately $5-10 \%^{(1)}$ compared with the general population for whom the prevalence is $1 \%$ in the USA ${ }^{(2)}$. Both conditions are related to inappropriate fluid intakes ${ }^{(3)}$. There is at present no information on the fluid balance of individuals with an SCI.

Total body water (TBW) and water turnover rates (WTR) of ten international-level wheelchair rugby players were determined using ${ }^{2} \mathrm{H}_{2} \mathrm{O}$ dilution and elimination. Participants had a median age of 31 (range 19-41) years and body mass of 66 (range 59.1-90.1) kg and all had an SCI above the 6th thoracic vertebra (T6). During the $6 \mathrm{~d}$ study all players participated in a $3 \mathrm{~d}$ tournament, playing two matches per $\mathrm{d}$. During the tournament, players spent $9 \mathrm{~h}$ in the gym, where mean temperature and relative humidity were $21.0(\mathrm{SD} 3.3)^{\circ} \mathrm{C}$ and $22(\mathrm{SD}$ 10) $\%$ respectively. On the other 3 da players undertook no formal exercise. Mean outdoor temperature during the study was 27 (SD 5$)^{\circ} \mathrm{C}$ and mean relative humidity 68 (SD 15$) \%$.

Median TBW was 32.7 (range 24.5-57.0) litres. Median TBW formed 48.2 (range 36.2-69.6) \% body mass; this value compares with a median of 70.1 (range $65.5-73.9) \%$ observed for competitive endurance cyclists ${ }^{(4)}$ and 63.5 (range 52.7-71.0) \% for a group of sedentary men of a similar age to the participants in the present study ${ }^{(4)}$. This finding would indicate a lower lean body mass, which is probably a result of muscle atrophy that occurs following SCI. Median WTR for the players was 3.3 (range 0.9-6.5) 1/d, or expressed relative to body mass 41 (range 15-56) ml/kg body mass per d; this value compares with medians of 47 (range 42-58) and 36 (range 29-50) ml/kg body mass per $\mathrm{d}$ observed for competitive endurance cyclists and sedentary men respectively ${ }^{(4)}$. Median $24 \mathrm{~h}$ urine output was 1.7 (range $0.3-$ $5.8)$ litres, which was significantly higher $(P<0.05)$ on the playing days $(1.9$ (range $0.5-5.8)$ litres) than on non-match days $(1.5$ (range 0.3-3.3) litres). Median non-renal losses were 1.5 (range 0.0-3.7) litres.

Individuals with a SCI have an impaired ability to thermoregulate as a result of an inability to secrete sweat ${ }^{(5)}$. Despite an impaired sweat response, the findings of the study indicate that the WTR of international wheelchair rugby players is similar to that of competitive endurance cyclists. It has been suggested that tetraplegics consume large volumes of fluid in order to tolerate increases in core temperature $^{(5)}$. It is also possible that individuals with SCI drink large volumes of fluid in an attempt to reduce the risk of a urinary tract infection. Tetraplegics suffer a greater number of hyponatraemic incidents both in the acute and chronic phases of injury compared with both general medical hospitalised patients and the free-living population of the USA ${ }^{(2,6)}$. Further complicating the fluid intake issue in those with an injury above T6 is the risk of autonomic dysreflexia if fluid intake becomes too great and causes bladder distension ${ }^{(7)}$. The present study provides descriptive data of the water turnover of athletes with an SCI.

1. Soni BN, Vaidyanthan S, Watt JW et al. (1994) Paraplegia 32, 597-607.

2. Lin M, Liu SJ \& Lim IT (2005) Emerg Med Clin North Am 23, 749.

3. Sica D \& Culpepper R (1989) Am J Med Sci 298, 331-333.

4. Leiper JB, Pitsiladis Y \& Maughan RJ (2001) Int J Sports Med 22, 181-185.

5. Price MJ \& Campbell IG (2003) Med Sci Sports Exerc 35, 1100-1107.

6. Peruzzi WT, Shapiro BA, Meyer PR Jr et al. (1994) Crit Care Med 22, 252.

7. Theisen D \& Vanlandewijck Y (2002) Cardiovascular responses and thermoregulation in individuals with a spinal cord injury. European bulletin of adapted physical activity; $\mathbf{1}, 1$ 